\title{
Supramolecular Assembly of Rigid-Flexible Block Molecules into Organized Nano-Structures
}

\author{
Ja-Hyoung Ryu, Byoung-Ki Cho, ${ }^{\dagger}$ and Myongsoo Lee ${ }^{\star}$ \\ Center for Supramolecular Nano-Assembly (CSNA), Department of Chemistry, Yonsei University, Seotl 120-749, Korea \\ "E-mail: mslee@yonsei.ac.kr \\ "Deparment of Chemistry, Dankook University, Seoul 140-714, Korea \\ Received Jine 23, 2006
}

\begin{abstract}
One of the most fascinating subjects in areas such as nanoscience and biomimetic chemistry is concerned with the construction of novel complex macromolecular and supramolecular nanoscopic architectures with well defined shapes and functions by using specifically designed organic building blocks. Supramolecular assemblies of rod like mesogenic molecules containing tlexible coils (rod-coil molecules) provide a facile entry into this area. In rigid-flexible block molecular system, the anisotropic orientation of the rod segments and the repulsion between the covalently connected blocks lead to self-organization into a wide variety of aggregation structures that can be manipulated by variation of the shape of the rigid segments, as well as the relative volume fraction of the rigid segment. Another interesting feature of rigid-flexible block molecules is their amphiphilic characteristic that can self-assemble into different aggregated structures via mutual interactions between block segments and solvent, depending on the solvent content and polarity.
\end{abstract}

Key Words : Rod-coil molecules, Supramolecules, Self-assembly, Nano-structures, Amphiphiles

\section{Introduction}

Well-ordered supramolecular materials with nanometerscale architectures have shown a variety of functionalities in material science, biochemistry, and catalyst science. ${ }^{1}$ Rational molecular design can create self-assembled nanostructures through weak intermolecular forces, such as hydrogen bonding, donor-acceptor interactions, repulsive interactions, and reversible ligand-metal interactions. ${ }^{2}$ Self-assembling molecules, which include liquid-crystals, ${ }^{3}$ block copolymers, ${ }^{4.5}$ hydrogen bonded complexes, ${ }^{6.7}$ and coordination polymers ${ }^{8-10}$ are widely studied for their great potential as advanced functional materials. Especially, the construction of novel supramolecular architectures with well defined shape and size by using rod building blocks is one of the most important subjects in organic materials chemistry because they can exhibit novel electronic and photonic properties as a result of both their discrete dimensions and three dimensional organization. ${ }^{11}$

Rod-coil systems consisting of rigid rod and flexible coil

Ja-Hyoung Ryu received his B.S.. M.S. and Ph. D. degrees in Chemistry from Yonsei University in 2000,2002, and 2006, respectively. He is curtently working as a postdoctoral associate in the Center for Supramolecular Nano-Assembly under the guidance of Professor Myongsoo Lee.

Byoung-Ki Cho received his B.S., M.S. and Ph. D. degrees in Chemistry from Yonsei University in 1997, 1999, and 2001, respectively. In $200 \mathrm{l}-2005$, he worked at Cornell University as a post-doctoral research fellow. Since 2005 he has worked as an Assitant Professor at Dankook University, segments are excellent candidates for creating well defined supramolecular structures via a process of spontaneous organization. ${ }^{12}$ The difference in chain rigidity of stiff rodlike and flexible coil-like block is expected to greatly affect the details of molecular packing and thus the nature of thermodynamically stable supramolecular structures. In order to balance these competing blocks, rod-coil molecules self-organize into a variety of supramolecular structures which can be controlled by variation of the rod to coil volume fraction (Figure 1). ${ }^{13}$

The careful selection of the type and relative length of the respective blocks can give rise to a variety of the welldefined supramolecular structures in nanometer-scale dimensions. ${ }^{14}$ Another interesting feature of rod-coil molecules is their amphiphilic characteristic that shows a strong tendency of their lipophilic and lipophobic segments to separate in space into distinct nanodomains. ${ }^{15}$ Depending on the solvent content and polarity, rod-coil molecules selfassemble into different aggregated structures via mutual interactions between block segments and solvent.

Myongsoo Lee received his B.S. degree in Chemistry at Chungnam National University (1981), M.S. degree at Korea University (1983) and, Ph.D. from Case Western Reserve University (1992). In 19921993, he worked at University of Illinois at Urbana-Champaign as a post-doctoral research fellow. In 1994 he moved to Yonsei University as an Assitant Professor, and then, in 2002 he was promoted to full Professor. He is the directior of National Creative Research Initiative Center for Supramolecular Assembly at Yonsei University (2002-present) and a recipient of Scientist of the Month Award from Korea Science \& Engineering Foundation (2006). 


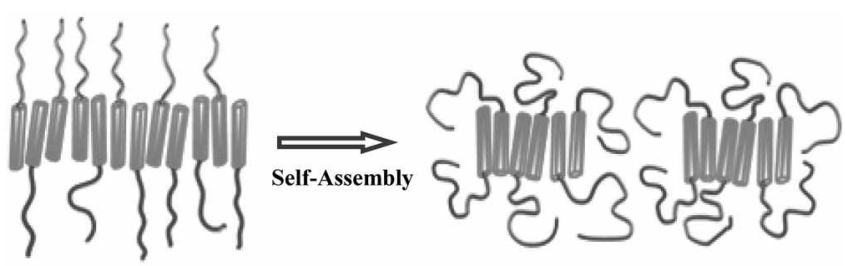

Figure 1. Self-assembly of the rod-coil molecules with increasing volume fraction of coil segments.

Based on these concepts, we have proved that a variety of different supramolecular structures can be formed by selfassembly of rigid rod building blocks with terminally attached flexible coils. These unique phase behaviors seem to originate from a combination of organizing forces including the mutual repulsion of the dissimilar blocks and packing constraints imposed by the connecting of each block, and the tendency of the rod block to form orientational order. ${ }^{14}$

This article deals with the molecules consisting of rigid rods and flexible coils, which are self-assembled into supramolecular aggregates with well-defined shape and size in nano-scale dimensions depending on various parameters such as molecular shape or solvent.

\section{Manipulation of Supramolecular Structure in Rigid-Flexible Diblock Systems}

\section{A. Variation of Rod-to-Coil Volume Ratio in AB}

Diblock Molecule. It is well known that the connection of oligo (alkylene ether) chains into a calamitic rigid rod at the temminals destabilizes the themotropic structures. ${ }^{3 k}$ However, stable supramolecular structures can be obtained by molecules with extended rigid rod segments as a result of the microphase segregation between the polar flexible oligo (alkylene oxide) ethers and rigid rod segments. ${ }^{25.16}$ In the case of rod-coil molecule with short rod-length, the coil segment may couple with the anisotropic rod owing to the relatively high miscibility between coil and rod segments, which can disturb the anisotropic aggregation of rod blocks. However, as the rod-length increases, the immiscibility between chemically different flexible and rigid chains increases. This allows the increasing lateral intermolecular interactions of rigid segments.

In a systematic work on the influence of the coil length on phase behavior, rod-coil molecules (1-3) with PPO having different degrees of polymerization but the identical rod segment were prepared. ${ }^{\text {ta.t. }}$ A dramatic structural change in the mesophase of this rod-coil system was observed with variation in the coil length as determined by a combination of techniques consisting of differential scanning calorimetry (DSC), optical polarized microscopy and X-ray scattering. Rod-coil molecule (1) with 7 propylene oxide (PO) repeating units exhibits layered structure, while rod-coil molecule (2) with 12 PO repeating units exhibits an optically isotropic cubic phase. This structure was identified by X-ray scattering method to be a bicontinuous cubic (cub) structure with $I a 3 d$ symmetry. Further increasing the coil length induces a hexagonal columnar mesophase as in the case of the molecule (3) with $20 \mathrm{PO}$ repeating units (Figure 2). Organization of the rod-coil molecules into a cross sectional slice of a cylinder for cubic and columnar phases gives rise to an aromatic core with approximately square cross section. The sizes and periods of these supramolecular structures are typically in a range of less than $10 \mathrm{~nm}$. This structural variation can be explained by considering the fact that increasing coil volume fraction leads to the structure with larger interfacial area, similar to well known conventional diblock copolymer phase behaviors. ${ }^{5,17}$

B. Variation of the Molecular Length at the Constant Rod-to-Coil Volume Ratio in AB Diblock Molecule. Another possible way to manipulate supramolecular structure should be provided by systematic variation in the rod length at the constant rod to coil volume ratio. Rod-coil molecules with different rod lengths represent to have the same rod volume fraction relative to coil segment $\left(f_{\text {rod }}=\right.$ 0.23) (Scheme 1). ${ }^{18}$

The systematic elongation of the rod segment leads to a structural transformation from a discrete bundle structure via a variety of intermediate structures including 3-D perforated lamellar and 2-D columnar structures to a lamellar structure. This interesting variation in the supramolecular structure, at an identical rod-to-coil volume ratio can be explained by

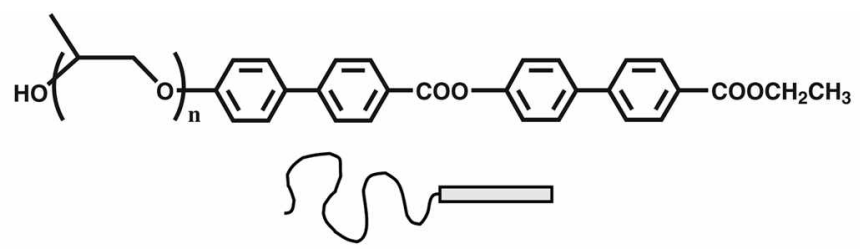

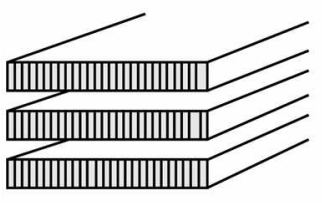

1 n 7 1-D Lamellar

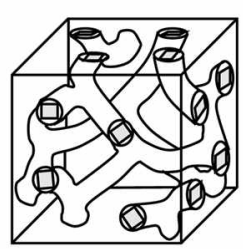

2 n 12 3-D Bicontinuous Cubic

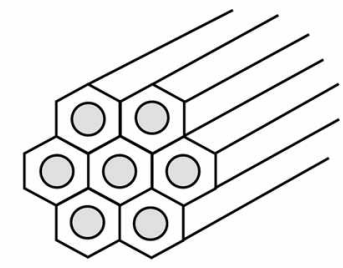

$3 n=20$ 2-D hexagonal Columnar

Figure 2. Self-assembly structures of the rod-coil diblock molecules by the increasing volume fraction of coil segments. 


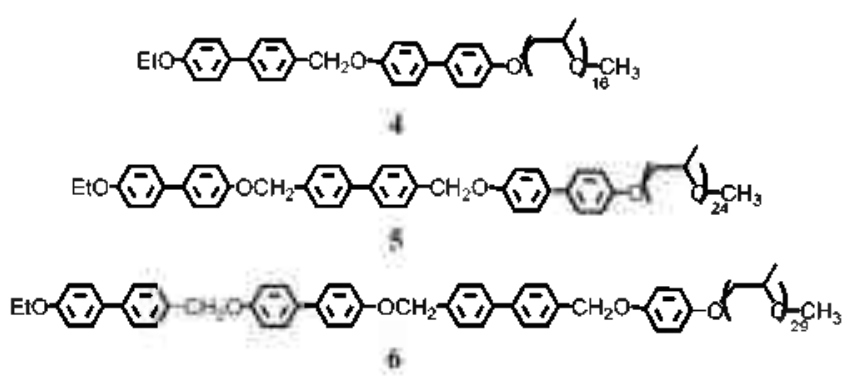

Scheme 1

considering the tendency of the rod building block to be arranged with their long axes. ${ }^{13 b-d, 19-21}$ On increasing the rod length, attractive interactions between the rod segments would be greater, which results in the organized structures with successive decrease in the interfacial area.

The aggregation structure of $\mathbf{4}$ based on a short rod length shows a 3-D discrete structure above a lamellar crystalline structure, most probably due to the relatively large entropic contribution to the free energy associated with a short molecular length (Figure 3). On elongation of the rod building blocks, the strong tendency of the rods to be aligned axially with their long axes makes a greater enthalpic contribution to the free energy balance at the expense of entropic penalties associated with coil stretching. Accordingly, the discrete domains would merge into a larger domain as in the case of $\mathbf{5}$ that self-assembles into infinitely long strips and tetragonally perforated layers, in order to reduce interfacial energy associated with unfavorable segmental contacts. Remarkably, further increasing the rod length gives rise to a hexagonally perforated layered structure as in the case of 6 . In addition, the hexagonal symmetry of the perforations in these molecules transforms to a tetragonal arrangement reversibly by changing temperature in these molecules, as illustrated in Figure 4. Therefore, changing temperature produces an effect similar to varying the molecular length. These results demonstrate that systematic variation of the rod length at an identical rod to coil volume fraction can provide a strategy to regulate the organized structure, from
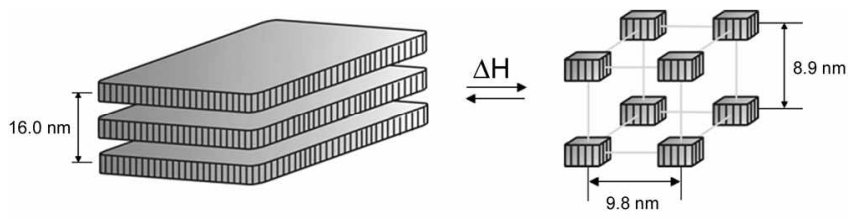

Figure 3. Self-asscinbly structures of 4 into I-D lancllar structure and 3-D tetragonal inicellar structure.
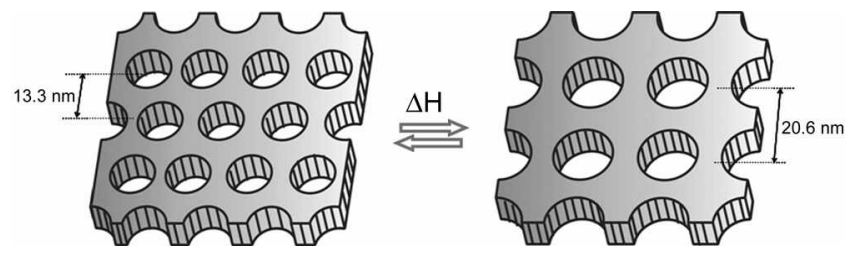

Figure 4. Self-assembly structures of 6 into a perforated lamellar structure with 3-D hexagonal lattice and 3-D tetragonal lattice. discrete bundles, long strips and, perforated layers with both tetragonal and hexagonal symmetries to conventional layers.

Compared to other self-assembling systems including block copolymers, ${ }^{4,5,22-24}$ liquid crystals, ${ }^{3}$ and surfactant systems, ${ }^{25-27}$ the unique feature of the structurally simple rod-coil diblock systems described here is their ability to self-assemble into stable perforated lamellar structures having different 3-D lattices with a small variation in the rod length. Furthermore, the 3-D symmetry of the coil perforation changes directly from a tetragonal to a hexagonal lattice in a reversible way with variation in temperature as in the case of 6. This transition may arise from the fact that, with increasing the rod length or lowering temperature, packing arrangement of coil perforations has a tendency to pack more densely. Consequently, the 3-D tetragonal lattice of coil perforations transforms into a 3-D hexagonal lattice that allows more close packing.

It is worthy of note that the perforated lamellar structures are equilibrium structures and thus, the 3-D lattice of the perforations can also be manipulated by a change in the rod length in a reversible way.

C. Variation of Molecular Shape: Tree-Shaped Molecule. Self-assembling molecules based on conjugated rod building blocks promise the opportunity to explore desired functions and properties as a result of aggregation into welldefined supramolecular architectures. ${ }^{11 k 28} \mathrm{~A}$ strategy to manipulate the aggregation structure assembled from a conjugated rod building block may be accessible by connecting hydrophilic, flexible dendritic branches to its one side, leading to a tree-shaped molecule.

The molecular tree ( 7 ) based on a small hydrophilic head self-assembles into a lamellar structure, whereas the molecule (8) containing a large head crystallizes into a discrete nanostructure that organizes into a $3-\mathrm{D}$ primitive orthorhombic supercrystal (Scheme 2). Furthernore, this orthorhombic nature with three characteristic dimensions together with a rectangular crystalline lattice suggests that the aggregation of 7 molecules in each aggregate generates the heptameric bundle with cross-sections that are more rectangular than circular in shape. Although the self-organization of rod building blocks into discrete bundles has been showed before, the shape of aggregate is in most cases oblate. Thus, a unique feature of $\mathbf{8}$ is the ability to self-assemble into heptameric bundles with prolate shape (Figure 5).

Amphiphilic block molecules, when dissolved in a selective solvent for one of the blocks, can self-assemble into a
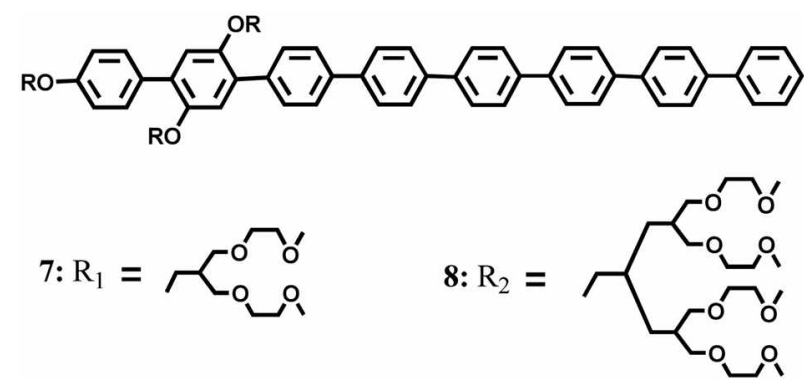

Scheme 2 

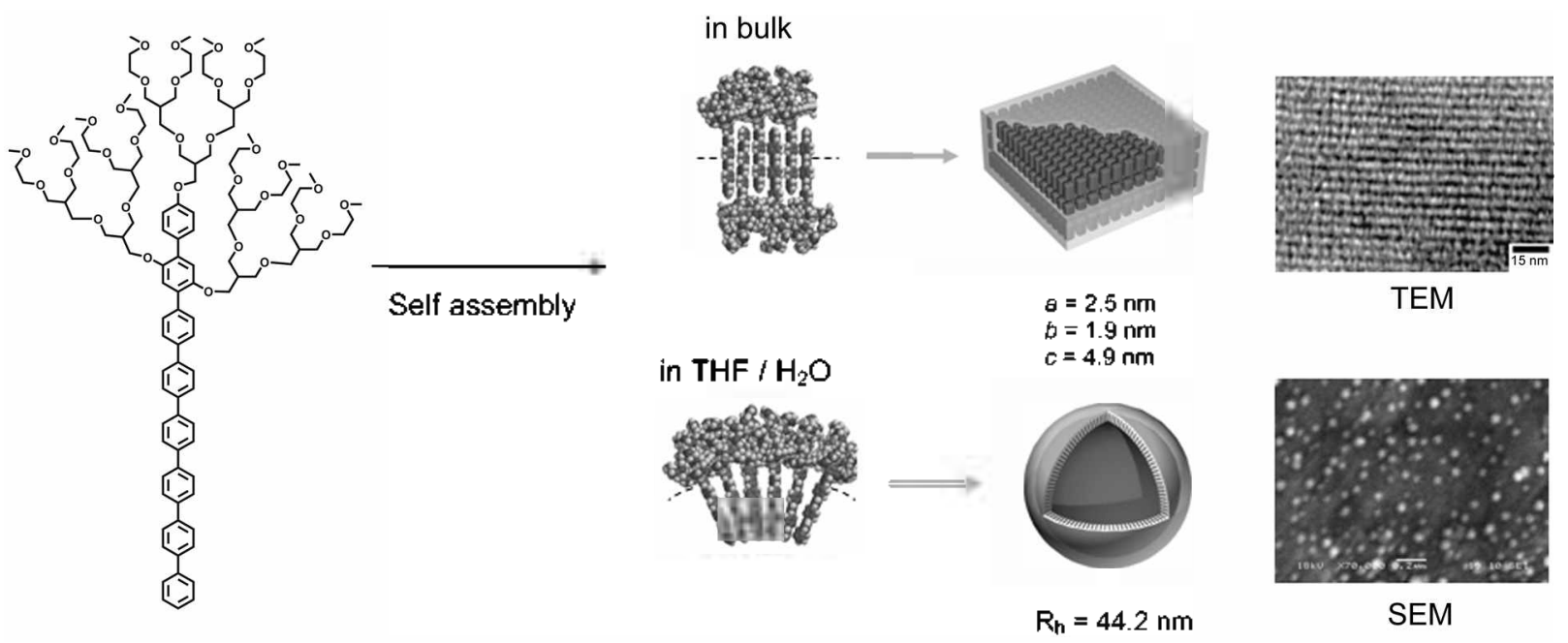

Figure 5. Self-assembly structures of $\mathbf{8}$ into the primitıve orthorhombic superlattice in bulk and vesicle structure in solution.

variety of aggregate structures, including vesicular structures. $^{29}$ The molecular trees are a new class of amphiphiles because it consists of a hydrophobic rod and a hydrophilic flexible head. The average hydrodynamic radii $\left(\mathrm{R}_{\mathrm{II}}\right)$ of the corresponding aggregates are approximately $100 \mathrm{~nm}$ for 7 and $46 \mathrm{~nm}$ for 8 , indicating that the molecular tree with a larger flexible head group assembles into a smaller size of aggregate. The radius of gyration of $\mathbf{8}$ is nearly identical to the hydrodynamic radius detemnined from dynamic light scattering, suggesting the existence of hollow spheres. ${ }^{30.31}$ As shown in Figure 5, the field-emission scanning electron micrograph (FE-SEM) shows spherical aggregates that are approximately $80 \mathrm{~nm}$ in diameter. It should be noted that the capsules preserve their hollow spherical morphology even after their isolation from the solution under high vacuum as evidenced by SEM experiment, indicating that the capsule formed in THF/water is remarkably stable. This stability of shape could be attributed to self-assembly of rigid building blocks with low confonnational entropy. ${ }^{290.32}$ These results demonstrate that rational design of self-assembling molecule based on a conjugated rod building block allows stable nanostructures to be produced, which potentially have a number of applications including the encapsulation and controlled release of active species and nanoreactors.

\section{Manipulation of Supramolecular Structure in Rigid-Flexible Triblock Systems}

\section{A. Introduction of Hydrophobic Chain in AB Diblock} Molecule. If chemically distinct hydrophobic chain is attached to the opposite end of rod segment, segregation of incompatible chain ends takes place and leads to an ordered phase composed of three distinct sub-layers. ${ }^{33}$ Coil-rod-coil $\mathrm{ABC}$ triblock molecules give rise to the formation of selfassembled structures with higher interfacial areas in comparison with $\mathrm{AB}$ diblock molecules. In contrast to that of diblock molecules based on $\mathrm{PEO}$ coil which show isotropic or smectic phase depending on the coil length, ${ }^{16.34 a}$ the $\mathrm{ABC}$ triblock molecule exhibits a hexagonal columnar mesophases. $^{14 \mathrm{C}}$ Molecule (10) with 22 ethylene oxide (EO) repeating units, for example, exhibits hexagonal columnar mesophase which, in tum, undergoes transformation into discrete spherical micellar structure in which rod segments are packed into discrete bilayer lamellar structure that is encapsulated with PEO coils (Figure 6). Small-angle X-ray diffraction in the optically isotropic state revealed a strong primary peak together with a broad peak of weak intensity at about 1.8 relative to the primary peak position, indicating that the spatial distribution of centers of the spherical micelles has only liquid-like short range order, most probably due to random thermal motion of spherical micelles. ${ }^{35}$ From the observed primary peak of X-ray diffraction, the diameter (d) of spheres was estimated to be approximately $12 \mathrm{~nm}$. Considering that diblock rod-coil molecule (9) with $22 \mathrm{EO}$ repeating units shows only an isotropic phase after crystalline melting, it is likely that hydrophobic force plays an important role in the self-assembly of the molecules into discrete nanostructures.

A novel strategy to manipulate the supramolcular nanostructure may be accessed by binding the $\mathrm{C}$ coil block of a coil-rod-coil $\mathrm{ABC}$ triblock molecule (10) into a tetrabranched triblock molecule (11) at a specific coil volume fraction. ${ }^{34 k}$ This binding may slightly modify the entropic contribution of the coil $\mathrm{C}$ part in the coil-rod-coil $\mathrm{ABC}$ system. In comparison with the monomer, the tetramer has restriction of chain end mobility through covalent linkage. Consequently, this effect may bring about the formation of a novel supramolecular nanostructure. Tetramerization of the molecule 10 provides an unusual example of the formation of a 3-D tetragonally perforated lamellar liquid crystalline phase as an intermediate phase between conventional lamellar and columnar structures (Figure 7). The supramolecular structure consists of liquid crystalline rod layers with inplane tetragonally ordered coil perforations stacked in an $\mathrm{AB}-\mathrm{BA}$ sequence. The perforations are likely to be filled by docosyl chains, most probably due to the large chemical 

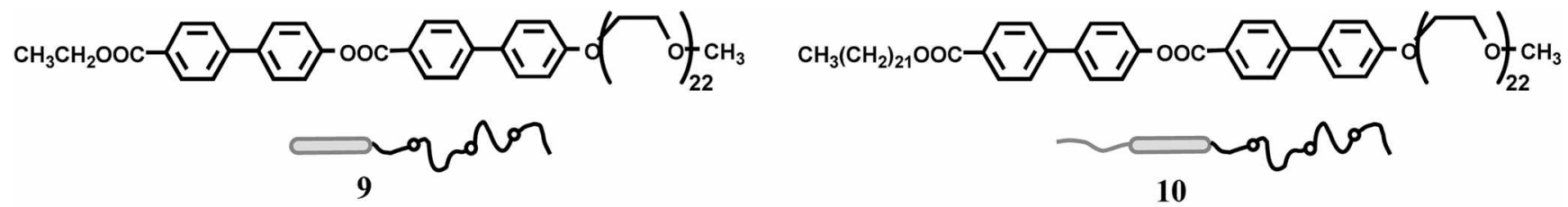

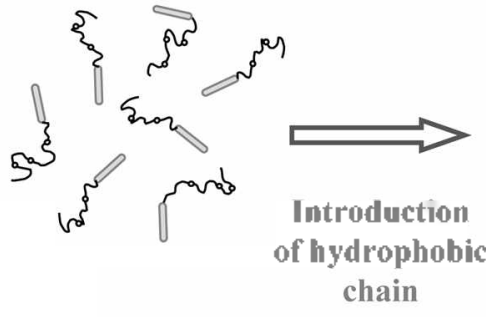

Liquid

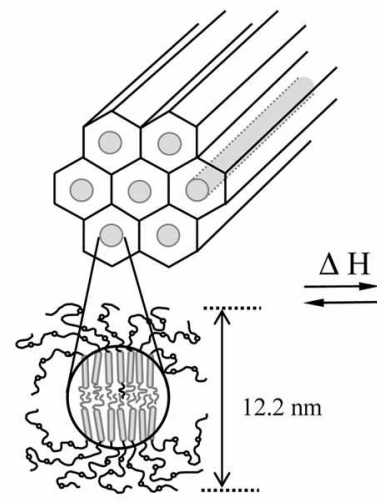

Column

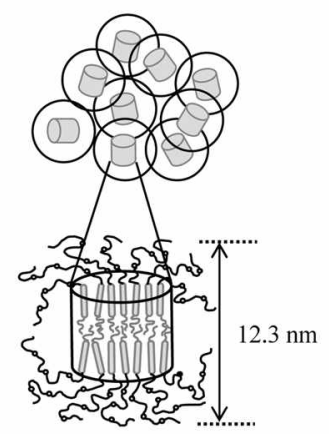

Spherical Micelle

Figure 6. Illustration of the induction of the mesophase in rod-coil molcculcs through hydrophobic force.
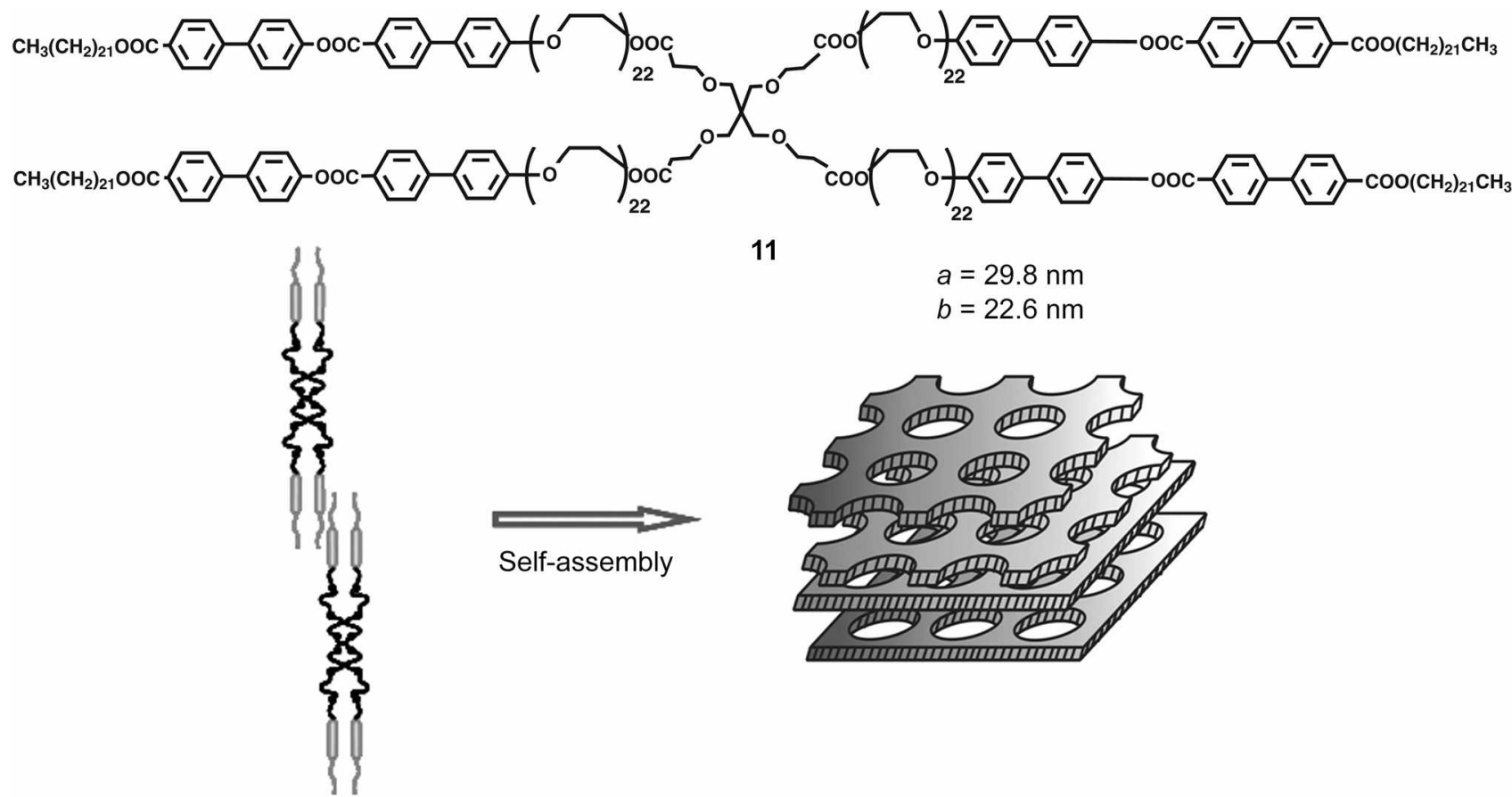

11

$a=29.8 \mathrm{~nm}$

$b=22.6 \mathrm{~nm}$

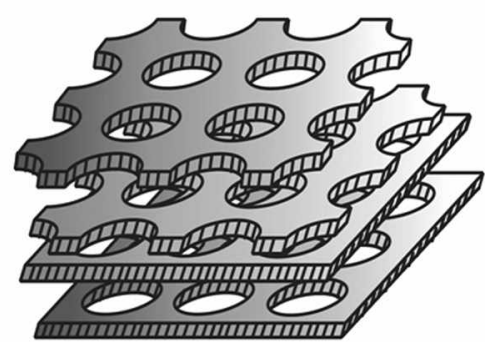

Figure 7. Self-assembly structures of 11 into the tetragonal perforated lamellar structure ( $14 / \mathrm{mm}$ space group symmetry) in an AB-BA sequence.

difference between the rod and poly(ethylene oxide) coil segments. The 3-D lattice is built up of two interpenetrating centered 3-D lattices. In comparison with the phase behavior of 10, the remarkable feature of $\mathbf{1 1}$ is that attachment of coilrod-coil molecules into a central point induces a perforated lamellar liquid crystalline phase with a $3-\mathrm{D}$ tetragonal symmetry that is thermodynamically stable. Upon melting of rod segments in 10, there is adequate free volume for the poly(ethylene oxide) to form a 2-D hexagonal columnar mesophase. Attachment of four poly(ethylene oxide) chains to a central point, however, has the effect of reducing the freedom of movement for the flexible chains, which in tum suppresses the ability of the rod segments to form a columnar mesophase with a larger interfacial area. Consequently, certain supramolecular structures with reduced interfacial area such as a perforated lamellar structure are preferred over the columnar phase exhibited by the monomer.

B. Variation of Rod-to-Coil Volume Ratio in ABA Triblock Molecule. In the case of symmetric coil-rod-coil molecule, the rod segment is connected with coil segments at both ends. This gives rise to the formation of the liquid crystalline structure with higher interfacial area in compari- 


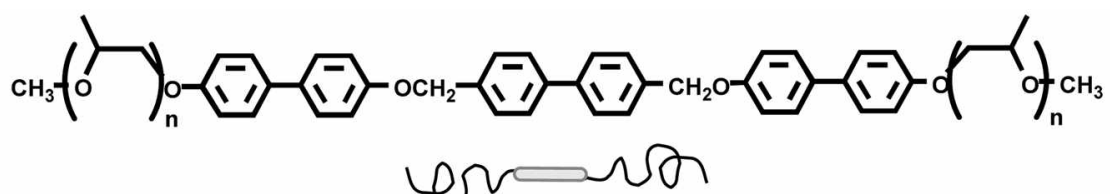

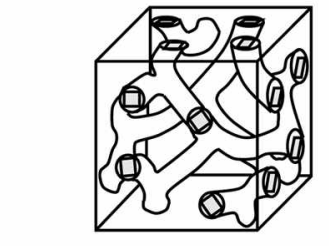

3-D BICONTINUOUS CUBIC $12 \mathrm{n}=3$

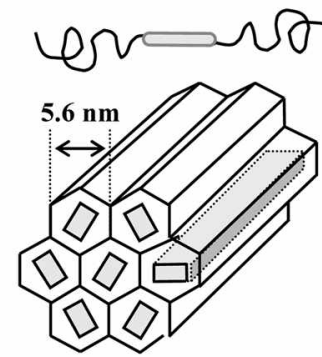

2-D COLUMNAR

$13 n=6$

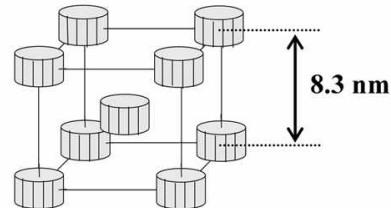

3-D TETRAGONAL

$14 n=13$

Figure 8. Self-assembly structures of the ABA coil-rod-coil triblock molecules.

son with rod-coil diblock systems at similar coil volume fraction. For example, the triblock molecule (12) with coil volume fraction, $f_{\text {coif }}=0.47$ exhibit a bicontinuous cubic phase instead of smectic phase. ${ }^{36}$ Similar to that of diblock rod-coil systems, increasing the volume fraction induces a hexagonal columnar mesophase as in the case of $\mathbf{1 3}$.

Remarkably, molecules with a longer length of coil (9-2 I PO repeating units) assemble into discrete supramolecular aggregates that spontaneously organize into a 3-D tetragonal phase with a body-centered symmetry in the solid state and mesophase as determined by small-angle X-ray scattering. Based on X-ray data and density measurement, the inner core of the supramolecular aggregate is constituted by the discrete rod bundle with a cylindrical shape with $5 \mathrm{~nm}$ in diameter and $3 \mathrm{~nm}$ in length that is encapsulated with phaseseparated PPO coils, which gives rise to the formation of non-spherical oblate aggregate (Figure 8). The supramolecular rod bundles subsequently organize into a 3-D bodycentered tetragonal symmetry. The oblate shape of supramolecular aggregates is believed to be responsible for the formation of unusual 3-D tetragonal phase $\left(\mathrm{M}_{\mathrm{te} 1}\right)$. This unique phase behavior is mostly originated from the anisotropic aggregation of rod segments with their long axes within microphase separated aromatic domains. Consequently, rod bundles with puck-like cylindrical shape would give rise to oblate micelles which can pack more densely into an optically anisotropic 3-dimensional tetragonal lattice, rather than an optically isotropic cubic lattice. These results demonstrate that the linear combination of flexible coils into both terminals of rod segment leads to discrete micellar aggregates which organized into a body centered tetragonal liquid crystalline phase above a certain coil volume fraction.

C. Variation of the Molecular Length at the Constant Rod-to-Coil Volume Ratio in ABA Triblock Molecule. Similar to that of diblock rod-coil systems, systematic variation in the molecular length at the constant rod to coil volume ratio are also enable to manipulate supramolecular structures of $\mathrm{ABA}$ triblock molecules. Especially, increasing the length of rod segment should disturb the assembly of the rigid rod segments into discrete bundles due to larger rod to rod interactions. Since the molecules have an identical rod to coil volume ratio $\left(f_{\text {rod }}=0.22\right)$ (Scheme 3 ), the shape change of the supramolecular structure may mainly be attributed to the variation in the chain length of the molecule. As mentioned above, the triblock molecule 14 based on three biphenyl units exhibits a tetragonal micellar liquid crystalline phase. In great contrast, the rod segment of 15 based on longer chain length self-assembles into a honeycomb like layered liquid crystalline phase $(\mathrm{HC})$ as a lower temperature mesophase in which hexagonally ordered perforations within a layer are filled by coil segments (Figure 9) ${ }^{37}$ These layers, in tum, are stacked spontaneously in $\mathrm{ABAB}$ fashion to generate a $3-D$ hexagonal order. A DSC heating trace of 15 shows a crystalline melting transition at $136^{\circ} \mathrm{C}$, followed by a birefringent liquid crystalline phase that undergoes transformation into another liquid crystalline phase at $157^{\circ} \mathrm{C}$. On heating to $157^{\circ} \mathrm{C}$, the honeycomb like mesophase transforms into a 3-D tetragonal micellar liquid crystalline phase.

Further increasing the length of rod segment suppresses the formation of a 3-D tetragonal mesophase, while induces only a honeycomb like liquid crystalline phase as in the case of the molecule 16. These results indicate that the selfassembled 3-D liquid crystalline phase changes significantly from organized rod-bundles in a coil matrix (tetragonal structure) to organized coil perforations in rod layers (honeycomb structure) on increasing the rod-length. This direct structural inversion is also accompanied by changing temperature. Therefore, changing temperature produces an effect similar to varying the molecular length. This example provides that the molecular length in rod-coil systems also has a large impact on the organized structure fomed by selfassembly of rod-coil molecules.

D. Variation of the Cross-Sectional Area of Coil Segment in ABA Triblock Molecule. The opposite way to modulate the supramolecular structure should be provided by variation in the coil structure but maintaining rod segment constant. To explore the influence of cross-sectional area of coil segment upon the se]f-assembly behavior of rod-coil system, $\mathrm{ABA}$ type coil-rod-coil molecules were prepared to have identical coil volume fraction $\left(f_{\text {coil }}=0.78\right)$ relative to mesogenic 


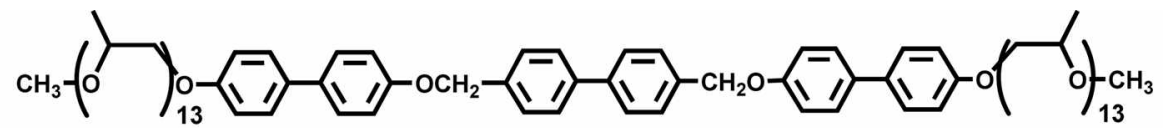

14

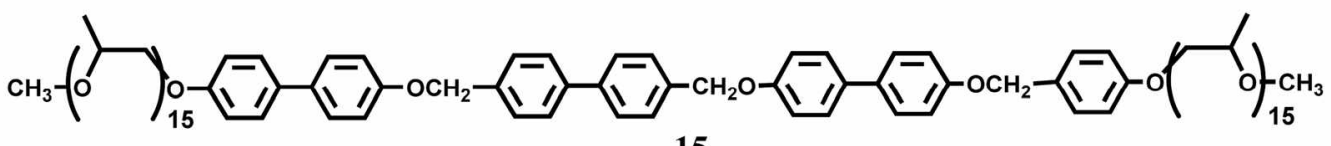

15<smiles>COc1ccc(-c2ccc(COc3ccc(-c4ccc(OCc5ccc(-c6ccc(COc7ccc(-c8ccc(O[C@@H](C)CC(C)OC)cc8)cc7)cc6)cc5)cc4)cc3)cc2)cc1</smiles>

16

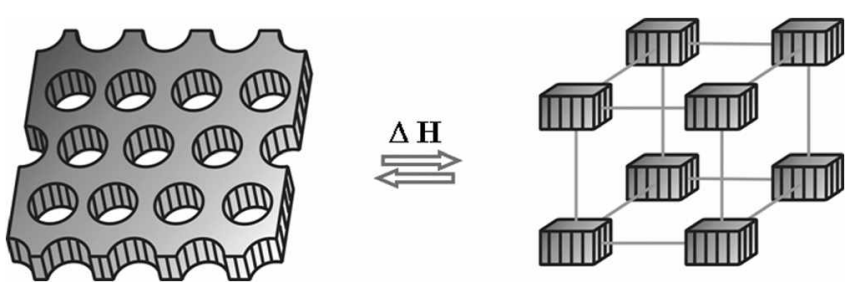

Figure 9. Self-assembly of rod-coil molccules into organized bundles (3-D body centered tetragonal structure) and organized honeycombs (3-D hexagonal structure).

rod segment, but different coil segments, i.e., poly(propylene oxide) and poly(ethylene oxide), respectively (Figure 10).

Compared to poly(propylene oxide) coil, poly(ethylene oxide) coil has a smaller cross-sectional area by lack of a lateral methyl group. As mentioned above, coil-rod-coil molecule 14 with PPO segments shows only a crystalline melting transition associated with rod segments. Coil-rodcoil molecule 17 with PEO segments, however, shows two crystalline states designated as $k_{1}$ and $k_{2}$. In the former $k_{1}$ state, both rod and PEO coil segments can be considered to be crystalline, while only rod segments to be crystalline in the latter $k_{2}$ state. After melting of rod segments, both molecules show the isotropic disordering transitions, suggestive of the existence of a liquid crystalline phase. 14 containing the PPO coils self-organizes into a 3-D body-centered tetra- gonal lattice, composed of the organized rod bundles and PPO coil matrix in both solid and mesophase. ${ }^{36}$ In contrast, 17 shows significantly distinct self-assembly behavior. On the basis of POM investigation, dendritic domains with striations that merge into an arced pseudo focal conic texture are exhibited on slow cooling from isotropic liquid phase (Figure 11). Furthermore, this texture is maintained in the $k_{2}$ state without abrupt change. This optical microscopic obser-

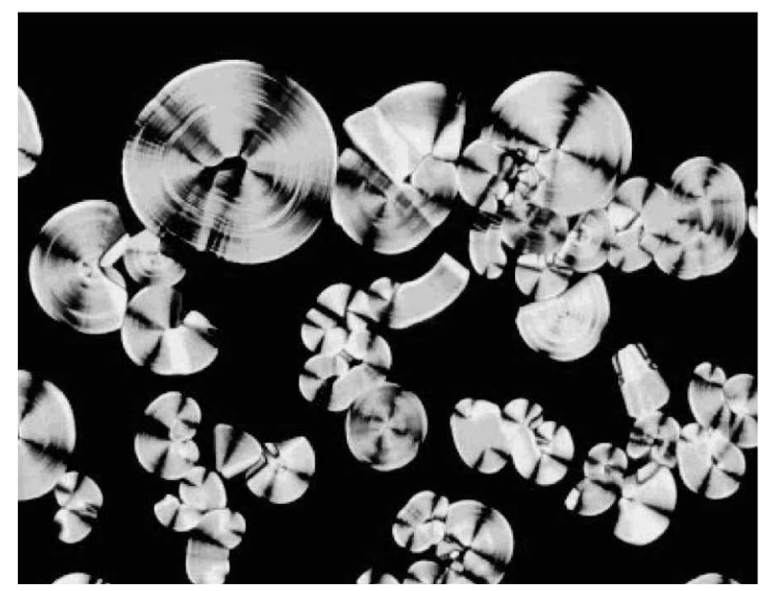

Figure 11. Optical polarized micrograph $(100 \mathrm{x})$ of the texture by the 3-D honeycomb-like lamellar liquid crystalline phase of 17 at $149^{\circ} \mathrm{C}$ on the cooling scan.

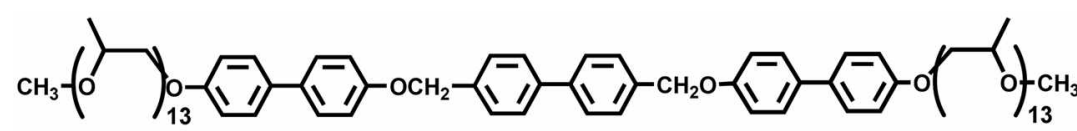

14: $\mathrm{k} 84.5 \mathrm{M}_{\text {tet }} 105.9 \mathrm{i}$

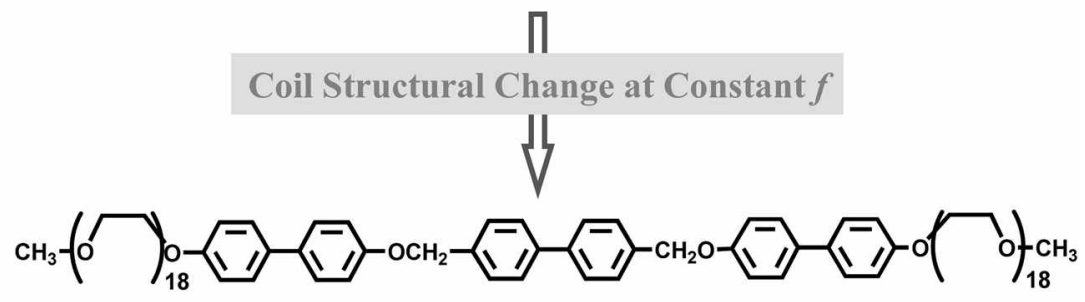

17: $\mathrm{k}_{1} 49.7 \mathrm{k}_{2} 131.0 \mathrm{HC} 152.0 \mathrm{j}$

Figure 10. Molecular structure and phase transition temperatures of coil-rod-coil molecules 14 and 17 (k: crystalline; $\mathrm{M}_{\mathrm{kc}}$. Body-centered tetragonal micellar; $\mathrm{HC}$ : honeycomb-like lamellar; i: isotropic). 
vation is strongly suggestive of a lamellar structure with hexagonally ordered coil perforations. ${ }^{37}$ On the basis of the POM observation and the SAXS data, the supramolecular structures in both crystalline and mesophases might be a honeycomb-like lamellar structure where hexagonally perforated layers ( $\left(P_{63} / m_{3}\right.$ symmetry) stacked in $\mathrm{ABAB}$ order.

The different self-assembly behavior of 14 and 17 with identical coil volume fraction points out the significance of coil cross-sectional area for the packing of rod segments. It can be rationalized by the consideration of coil density at $\mathrm{rod} / \mathrm{coil}$ interface dependent upon coil cross section. For a given space at rod/coil junction, the coils with larger crosssectional area cause more space crowding. The steric repulsion resulted from the space crowding leads to the stretched conformation of coils, leading to the coil stretching penalty. ${ }^{13 \mathrm{c}}$ The morphological transition from continuous (the honeycomb-like lamellar structure of 17) into discrete rod packing structures (the tetragonal structure of 14 ) allows coils enough room to lower the coil conformational energy. Finally, self-assembly of rods can be fine-tuned in 3-D nanospace since, in addition to coil volume fraction, coil cross section is an independent parameter to build a variety of supramolecular structures.

E. Variation of the Side Groups of Rod Segment in ABA Triblock Molecule. A strategy to manipulate the aggregation structure assembled from a rod building block may be accessible by incorporation of side groups into a rod block. ${ }^{38}$ The side groups could lead to loose packing of the extended rod segments, which may modify the resulting supramolecular structure. A coil-rod-coil molecule consisting of five biphenyl units connected through ether linkages as a rod block and poly(propylene oxide) ( $\mathrm{PPO}$ ) coils with the number of repeating units of 17 (Scheme 4), selfassembles into hexagonal perforated layers stacked in $\mathrm{ABAB}$ order in the melt. ${ }^{18.39}$

In contrast, a coil-rod-coil molecule containing methy] side groups in its center shows an unusual supramolecular structural inversion, from perforated layers to discrete bundles, while maintaining a 3-D hexagonal superlattice (Figure 12). The small-angle $\mathrm{X}$-ray diffraction pattern of $\mathbf{1 8}$ in the melt showed a number of well-resolved reflections, which can be indexed as a 3-D hexagonal order $\left(\mathrm{P}_{3} / \mathrm{mm}\right.$ c space group symmetry) with lattice constants $a=8.2 \mathrm{~nm}$ and $c=$ $14.4 \mathrm{~nm}$, indicating that 18 exhibits a 3-D perforated lamellar mesophase. Similar to that of 18 , the small-angle Xray diffraction pattem of 19 in the solid state showed reflec- tions corresponding to a 3-D hexagonal perforated lamellar structure with lattice constants $a=9.5 \mathrm{~nm}$ and $c=16.5 \mathrm{~nm}$. Interestingly, the small-angle X-ray diffraction patten in the melt recorded at $145^{\circ} \mathrm{C}$ showed more separated two strong reflections, together with several reflections with low intensity at higher angles, assigned as a 3-D hexagonal structure with lattice constants $a=8.8 \mathrm{~nm}$ and $c=15.0 \mathrm{~nm}$. However, the peak intensities indexed as 101 and 102 reflections appeared to be very strong, as opposed to those of a hexagonally perforated lamellar structure. ${ }^{18.39}$ This result suggests that the fundamental structure of the 3-D hexagonal structure in the melt is based on discrete bundles rather than perforated layers. ${ }^{\text {to }}$

The TEM image of a microtomed film (stained with $\mathrm{RuO}_{4}$ ) showed a honeycomb supramolecular structure with a hexagonal array of light coil perforations in a dark rod matrix (Figure 13a). In contrast, the image of a cryo-ultramicrotomed film after annealing at $145{ }^{\circ} \mathrm{C}$ showed a hexagonal array of dark rod domains in a light coil matrix (Figure 13b) ${ }^{40 a}$ This phase transition on heating is most probably due to larger entropic contribution to the free energy associated with coil stretching. ${ }^{13 c, 20}$ in comparison with the mesophase structure of $\mathbf{1 8}$, this indicates that the introduction of methyl side groups into a rod segment leads to the transformation of a 3-D hexagonal perforated lamellar structure into a 3-D hexagonally organized discrete bundles. This notable feature is that the incorporation of alkyl side groups into the center of a rod segment generates the structural inversion from organized coil perforations in rod layers to organized discrete rod-bundles in a coil matrix, while maintaining a 3-D hexagonal superlattice. It is also remarkable that this structural inversion, retaining a 3-D hexagonal superlattice, occurs directly without passing

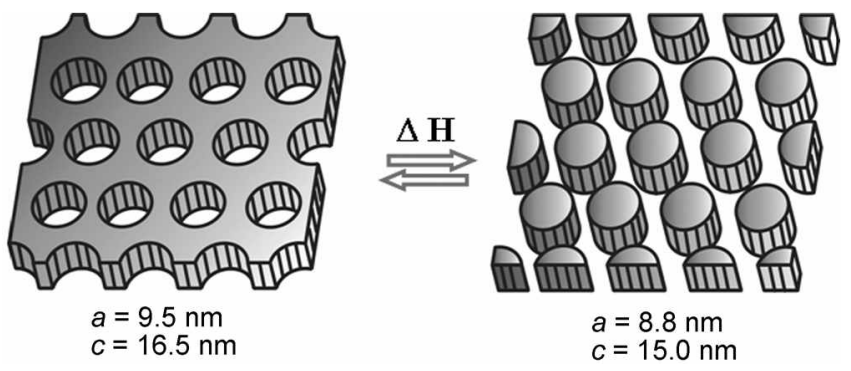

Figure 12. Self-assembly of coil-rod-coil molecule 19 into the hexagonal perforated layer crystalline phase and subsequent conversion to hexagonal close-packed bundles.

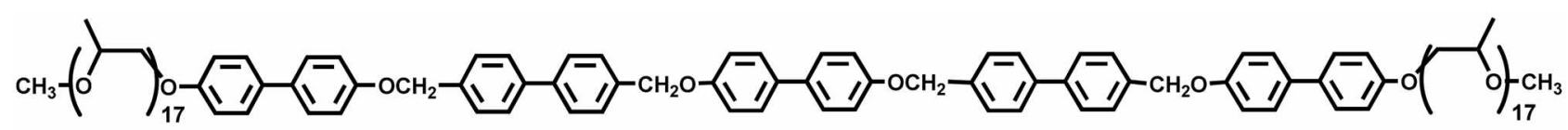

18

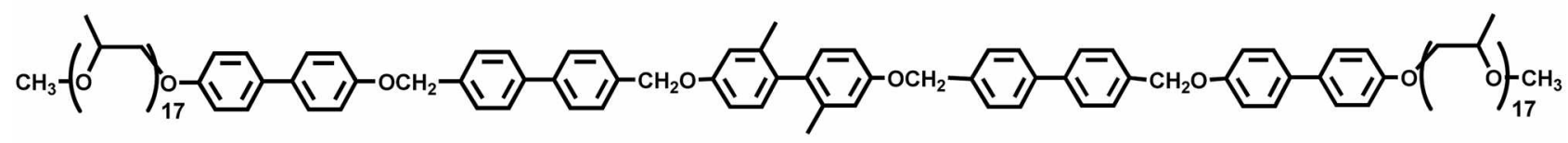



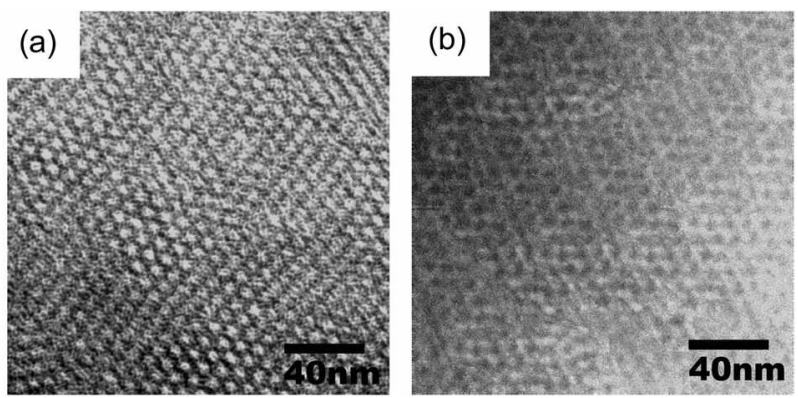

Figure 13. Transmission electron micrographs of ultramicrotomed thin films of 19 stained with $\mathrm{RuO}_{4}$, revealing the fornation of a well-ordered (a) hexagonal perforated layer structure with nanoscale dimensions, the light regions correspond to the coil domains, the dark regions to the rod matrix; (b) hexagonal closepacked structure, the light regions correspond to the coil matrix, the dark regions to the rod domains.

through any intermediate structures in a reversible way by changing temperature, as evidenced by structural behavior of 19 . This abrupt structural change in rod-assembly may offer an attractive potential for use in supramolecular switch and thermal sensor.

F. Variation of Molecular Shape; ABC Triblock Rigid Wedge-Flexible Block Molecules. Dendritic units are attractive building blocks to form supramolecular architectures because they are well-defined in molecular architecture. ${ }^{+1}$ Incorporation of such a dendritic building block into the end of an incompatible linear chain gives rise to novel self-assembling systems because the molecule shares certain general characteristics of both block copolymers and small amphiphiles. ${ }^{42}$ For example, polystyrene-dendrimer block copolymers have been reported to self-assemble into a wide variety of supramolecular structures in aqueous solution, from spherical micelles, micellar rods, to vesicular aggregates as a function of generation. ${ }^{43}$ Amphiphilic dendrimers containing an extended rigid block represent another class of self-assembling systems that are increasingly used for the construction of supramolecular architectures with welldefined shape. The introduction of a hydrophobic docosyl chain and hydrophilic dendrimer into each end of an extended rigid segment would give rise to a unique amphiphilic $\mathrm{ABC}$ triblock system consisting of a hydrophilic dendritic block, rigid aromatic, and hydrophobic docosyl chain. In this system, an extremely stiff, hydrophobic block is expected to contribute not only to self-assemble into an ordered structure in the bulk, but also to form a stable aggregation in an aqueous solution. $\mathrm{ABC}$ triblock rigid aromatic-flexible dendritic block molecules consist of a docosyl chain, Yshaped rigid aromatic segment, and flexible poly(ethylene oxide) dendrimer that is soluble in water and a number of organic solvents (Figure 14).

The small-angle X-ray diffraction patten of $\mathbf{2 0}$ displays sharp reflections that correspond to a 2-D hexagonal columnar structure with a lattice constant of $8.1 \mathrm{~nm}$. This dimension implies that the more rod-like rigid segments arrange axially with their preferred direction within a cross-sectional slice of the column, in which docosyl chains pack in an interdigitated fashion and distort conformationally (Figure 14). In contrast, the small-angle X-ray diffraction pattern of $\mathbf{2 1}$ shows a strong reflection together with a number of low intensity reflections at higher angles, indexed as a 3-D bodycentered cubic phase with a lattice parameter of $11.6 \mathrm{~nm} .^{44}$ Considering the space filling requirement and cone-shaped building block, the radial arrangement of the rigid segments is expected to be the best way to close pack the hydrophobic core, leading to a discrete nanostructure. ${ }^{35,12 a, 44}$ Accordingly, 21 based on a more wedge-like aromatic segment can be described to self-organize into an optically isotropic cubic phase consisting of a 3-D body-centered arrangement of discrete aggregates, as shown in Figure 14.

Dendritic molecules containing rigid aromatic segments can be considered as a new class of amphiphiles because they consist of a hydrophobic rigid segment and a hydrophilic flexible dendrimer. As a result of their amphiphilic characteristics, the rigid-dendritic block molecules can encapsulate hydrophobic guest molecules in an aqueous environment. The average hydrodynamic radii $\left(R_{H}\right)$ of the corresponding aggregates encapsulated a hydrophobic solv-
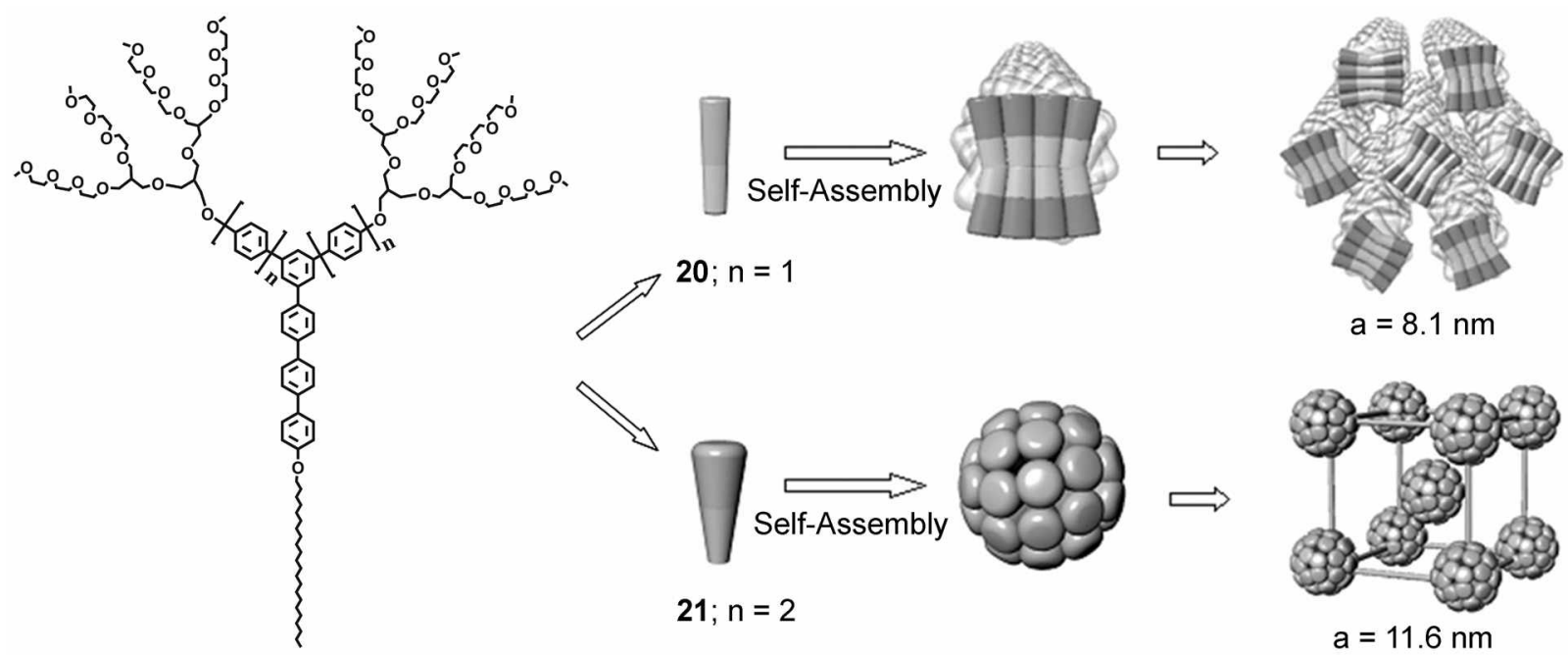

Figure 14. Schematic representation for (a) the hexagonal columnar structure of $\mathbf{2 0}$ and (b) the body-centered cubic structure of 21. 
ent within the micellar aggregate, increase with an increase in the $\mathrm{CHCl}_{3}$ content, suggesting that hydrophobic guest molecules are encapsulated within the hydrophobic micellar core. The measured diameters $(100 \mathrm{~nm})$ exceed the extended molecular length (approximately $5 \mathrm{~nm}$ ) by a factor of about 20 , suggesting that these aggregates encapsulate $\mathrm{CHCl}_{3}$ molecules within their hydrophobic interior (Figure 15). Supramolecular capsule-like aggregates and their ability to encapsulate hydrophobic guest molecules offer an attractive potential for use in a wide variety of applications ranging from controlled drug release, solubilization of hydrophobic molecules in aqueous media, to the design of nanoreactors.

\section{Manipulation of Supramolecular Structure in Rigid-Flexible Multiblock Systems}

A. Variation of Rod-to-Coil Volume Ratio. The rod-coil approach as a means to manipulate supramolecular structure as a function of rod volume fraction was reported to be extended to main chain multiblock copolymer systems which generate bicontinuous cubic and hexagonal columnar mesophases depending on the rod-to-coil volume fraction. ${ }^{1 \downarrow d<}$ For example, rod-coil multiblock copolymer (22) based on short length of coil (rod volume fraction, $f_{\text {rod }}=0.38$ ) exhibits a bicontinuous cubic mesophase, while copolymer (23) based on higher coil volume fraction $\left(f_{\text {rod }}=0.29\right.$ ) shows a hexagonal columnar mesophase. A notable feature of this system is the ability of the main-chain liquid crystalline polymers based on a rod building block to self-assemble into ordered structures with curved interfaces. Fonnation of supramolecular columnar and bicontinuous cubic assemblies in the rod-coil copolymers is in marked contrast to general behavior of conventional liquid crystalline polymers based on rod-like mesogens and segmented copolymers based on altemating rigid and flexible segments. ${ }^{27+55}$ Fonnation of the ordered structures with interfacial curvature from the main-chain rod-coil copolymers can be rationalized by considering entropic penalties associated with coil stretching and anisotropic arrangement of rod segments. Bulky PPO coils induce curvature at the rod/coil interface, arising from the connectivity of the rod and coils, constraint of constant density, and

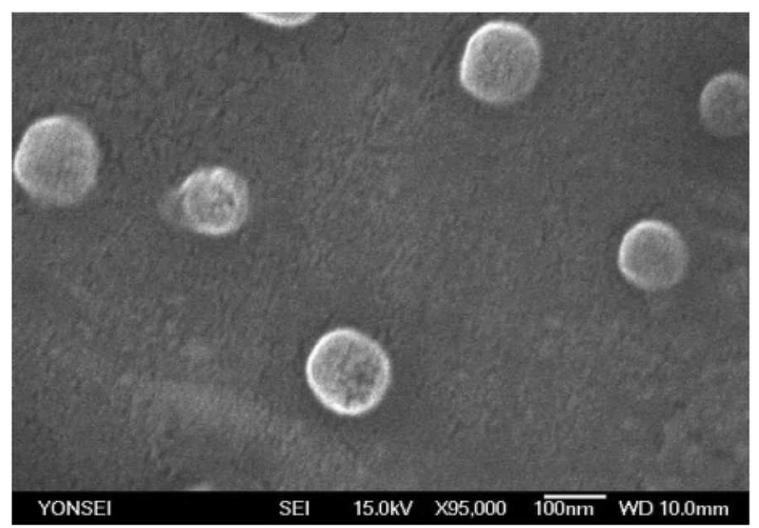

Figure 15. SEM inage of the capsules formed by $20\left(5 \times 10^{-3} \mathrm{~g} /\right.$ $\mathrm{mL})$ in $\mathrm{H}_{2} \mathrm{O}$ in the presence of $\mathrm{CHCl}_{3}\left(1 \times 10^{-2} \mathrm{~mL} / \mathrm{mL}\right)$. minimization of coil stretching. At the interface separating the rod and coil domains in the layered smectic structure, the relatively smaller area per junction favored by rod block results in chain stretching of the coil block, which is energetically unfavorable. Therefore, the rod-coil copolymers selfassemble into bicontinuous cubic or hexagonal columnar structures with larger interfacial area, instead of a layered smectic structure (Figure I6).

B. Variation of the Number of Grafting Sites per Rod at the Constant Rod-to-Coil Volume Ratio. In contrast to this, another strategy to manipulate the supramolecular structure at constant rod-to-coil volume ratio can also be accessible by varying the number of grafting sites per rod which might be closely related to the grafting density at the interface separating rod and coil segments. For this reason, 24, 25 and 26 with rod-coil repeating units consisting of three biphenyl units connected by methylene ether linkages as the rod block and PPO with 13 PO repeating units as the coil block were prepared (Scheme 5). ${ }^{+6}$

All of the oligomers are self-organized into ordered supramolecular structures that differ significantly on variation of the number of repeating units as confirmed by $X$-ray scattering. The molecule $\mathbf{2 4}$ shows a bicontinuous cubic liquid crystalline structure. In contrast, the molecule 25 shows a 2 $\mathrm{D}$ rectangular crystalline and a tetragonal columnar $\left(\mathrm{Col}_{1}\right)$ jiquid crystalline structures, while the molecule 26 displays a hexagonal columnar structure in both their solid state and mesophase (Figure 17). These results represent that selfassembled liquid crystalline structures, from 3-D bicontinuous cubic, 2-D tetragonal to 2-D hexagonal lattices are formed by rod-coil structures that differ only in the number of repeating units.

This interesting variation of self-assembled structures, at an identical rod to coil volume ratio, can be explained by

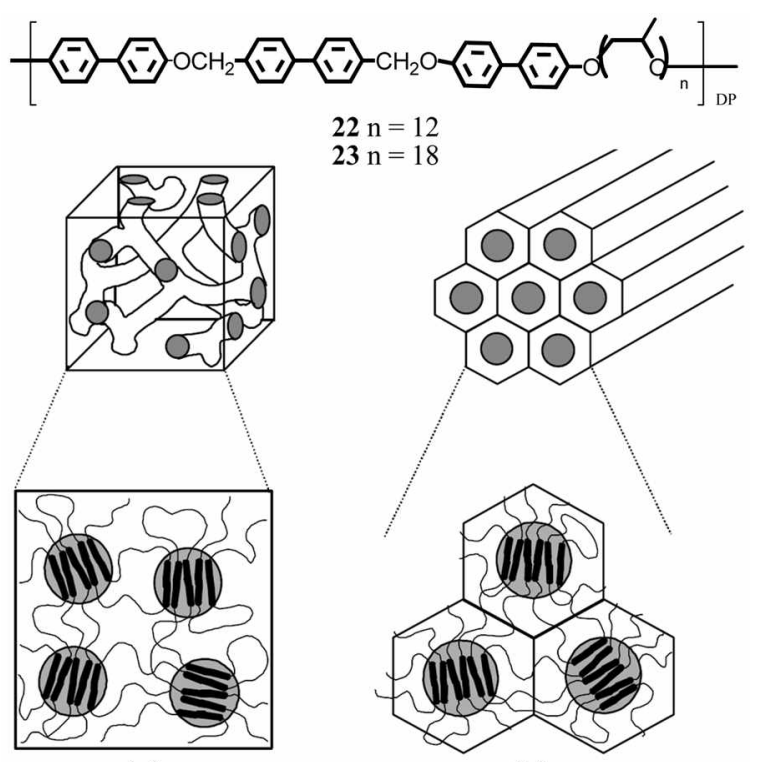

(a)

(b)

Figure 16. Self-assemblies of rod-coil multiblock copolymers in (a) the bicontinuous cubic of $\mathbf{2 2}$ and (b) the hexagonal columnar phases of 23. 

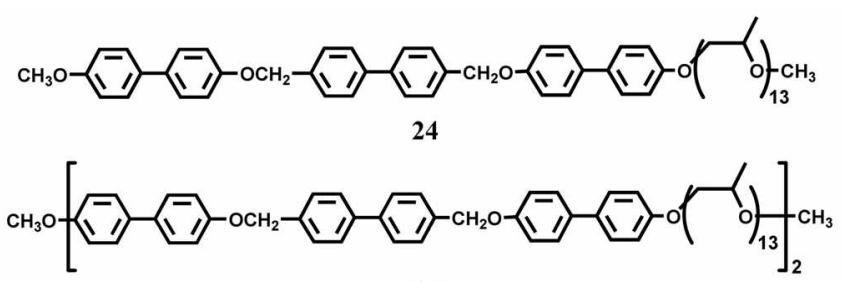

25

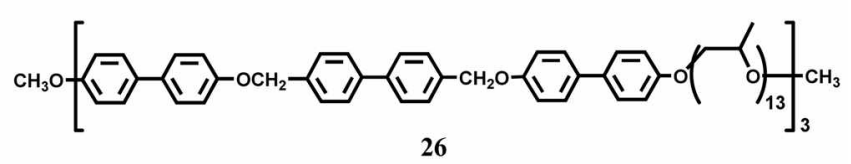

Scheme 5

considering the density of grafting sites at the interface separated by rod and coil. On increasing the number of rodcoil repeating unit, the density of grafting sites at the interface will be increased due to an increase in the average number of coils grafted to a rod, which results in strong entropic penalty associated with coil stretching at the rodcoil interface. To reduce this coil stretching, a bicontinuous cubic structure of the monomer would break up into 2-D cylindrical domains in which less confinement and deformation of coil segments occur. These results demonstrate that systematic variation of the number of repeating units in the rod-coil multiblock oligomers can provide a strategy to regulate the liquid crystalline phase, from bicontinuous cubic, 2-D tetragonal columnar to 2-D hexagonal columnar structure.

C. Variation of Molecular Shape: $m$-Linked RigidFlexible Multiblock Molecules. Conformationally flexible, $m$-linked rigid monomers containing a flexible side group have polymerized with 4,4 '-bis(bromomethyl)biphenyl to yield $m$-linked aromatic polymers. Notably, the secondary structure of the resulting polymers appears to be dependent on the molecular structure of the side group in the solid state. Polymer 27 based on a linear side chain appears to selforganize into a lamellar structure based on an unfolded confonmation with a lattice dimension of $5.5 \mathrm{~nm}$. The lamellar structure with this dimension indicates that the rigid polymer chain of 27 adopts an unfolded zigzag conformation. In great contrast, polymer 28 based on a bulky dendritic side group self-assembles into a $2-D$ tetragonal structure ( $P 4 m m$ space group) with a lattice parameter of 3.6 nm based on a helical conformation (Figure 18). Compared to 27 , the bulky dendritic geometry of the flexible segments relative to a linear chain is likely to prohibit the $2 \mathrm{D}$ growth of a self-assembled structure. Instead, the polymer chains containing bulky dendrons are strongly driven to aggregate in one dimension with a helical packing through microphase separation between the rigid aromatic core and flexible

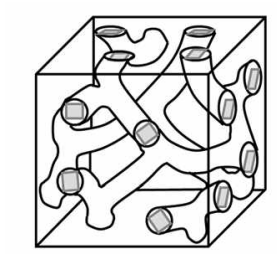

BICONTINUOUS CUBIC

24

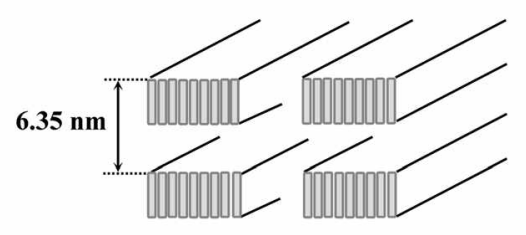

RECTANGULAR COLUMN

25

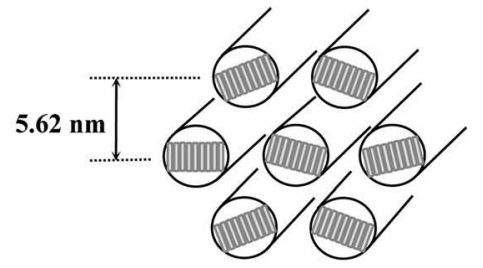

HEXAGONAL COLUMN

26

Figure 17. Self-assemblies of rod-coil multiblock molecules depending on the rod-coil repeating unit.
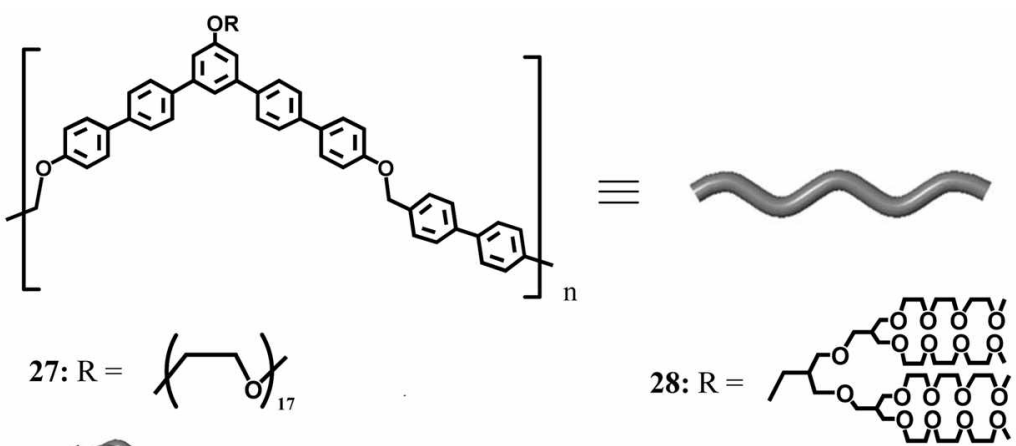

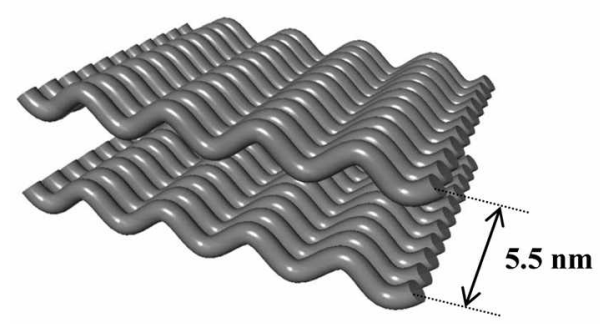

LAMELLAR

27: $\mathrm{R}={ }_{0}$

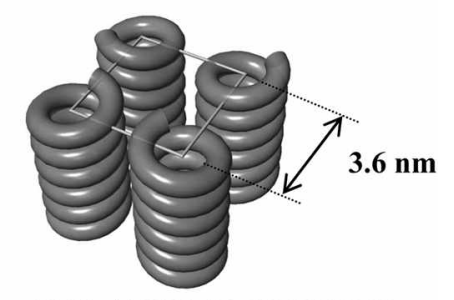

RECTANGULAR COLUMNAR

Figure 18. Self-assemblies of m-linked multiblock molecules depending on the bulkiness of coil segment. 


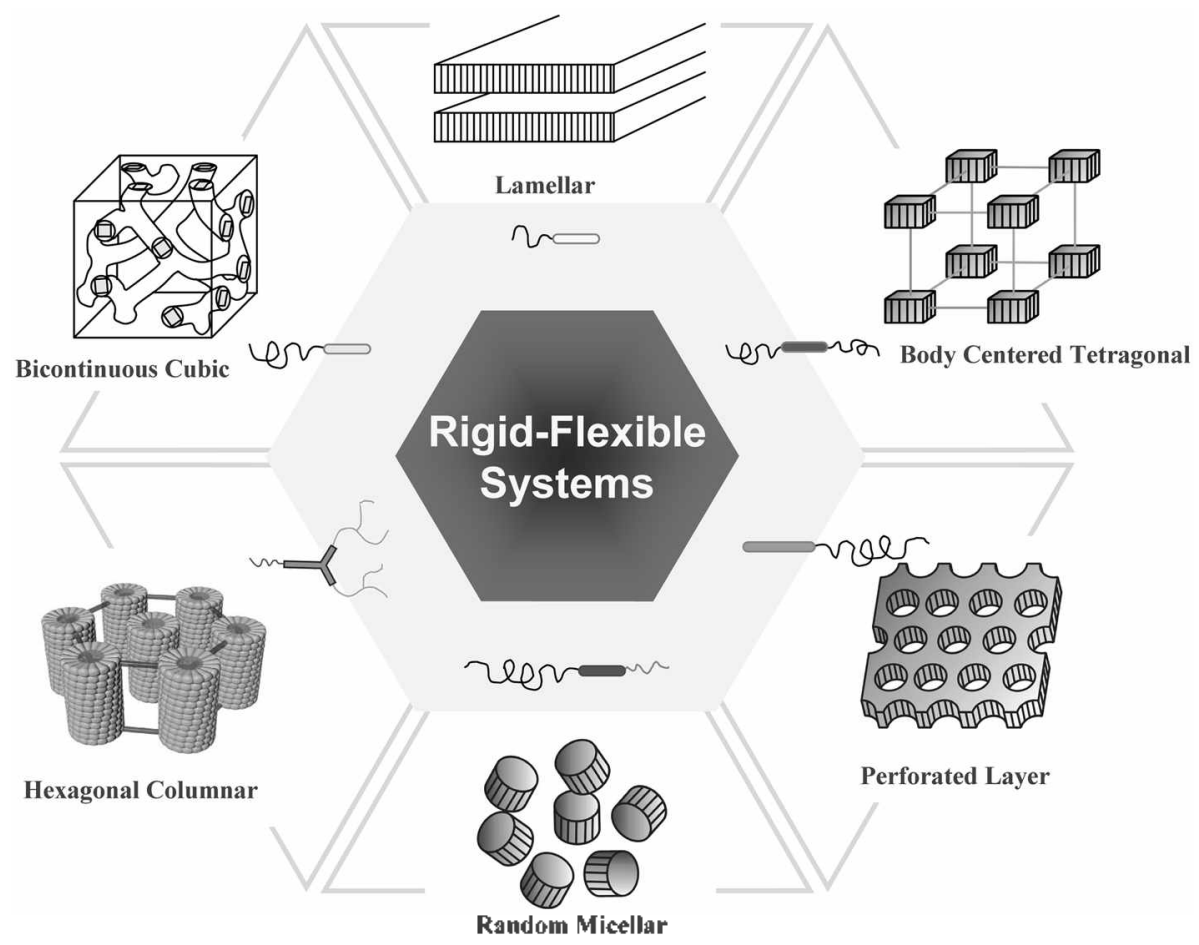

Figure 19. Various supramolecular structures formed by self-assembly of rigid-flexible block molecules.

dendron segments and $\pi$ - $\pi$ stacking interactions between aromatic units in order to relieve steric repulsions between bulky dendrons. ${ }^{47}$

The secondary structure of polymer chains based on the connection of aromatic moieties in a meta geometry can be controlled from a folded helical conformation to an unfolded conformation by attaching chemically dissimilar, flexible dendrons as a side groups. As the cross-sectional area of the dendritic wedge of the polymer increases, greater steric repulsion between adjacent dendritic wedges could possibly cause a transformation into a helical conformation in order to relieve the repulsive forces. This implies that introduction of bulky side groups into a polymer based on a meta geometry can give rise to the formation of a folded secondary structure.

\section{Concluding Remarks}

A variety of different supramolecular structures can be formed by self-assembly of mesogenic rod building blocks with terminally attached polyether coils. This unique phase behavior seems to originate from a combination of organizing forces including the mutual repulsion of the dissimilar blocks and packing constraints imposed by the connecting of each block, and the tendency of the rod block to form orientational order. The supramolecular structures formed by rod segments in rod-coil systems include 1-D lamellar, 2-D columnar, 3-D bicontinuous cubic, 3-D micellar tetragonal, 3-D micellar cubic, 3-D random micellar and even 3-D honeycomb phases (Figure 19).

Another remarkable feature of rod-coil molecules is their amphiphilic characteristics that show the tendency of their liphophilic and liphophobic parts to segregate in space into distinct microdomains. Depending on the solvent content and polarity, rod-coil molecules self organize into different structures from micelle to hollow vesicle. It can also be expected that many more rod-coil systems which can assemble into nove] supramolecular structures such as giants vesicles or artificial cells for possible applications as diverse as self-assembled materials for nanotechnology, periodic porous materials, biomimetic materials and optoelectronic nanomaterials will be developed in the near future.

Acknowledgements. This work was supported by the National Creative Research Initiative Program of the Korean Ministry of Science and Technology, Seoul R\&BD Program (10668) and the Korea Science and Engineering Foundation (R01-2006-000-11221-0).

\section{References}

I. Lehn, J. M. Stupramolecular Chemistry, Concepts and Perspectne; VCH: Weinheim, Germany, 1995.

2. (a) Lee, M.; Cho, B.-K.; Zin, W.-C. Chem. Rev: 2001, 101, 3869. (b) Klok, H.-A.; Lecommandoux, S. Ad, Mater. 2001, 13, 1217 . (c) Stupp, S. I.; Pralle, M. U.; Tew, G. N.; Li, L.; Sayar, M.; Zubarev, E. R. MRS Bull. 2000, 42. (d) Loos, K.; Munoz-Guerta, S. Microstructure and Crystallization of Rigid-Coil Conblike Polymers and Block Copolymers in Supramolecular Polymers; Marcel Dekker: New York, 2000; Chapter 7.

3. (a) Collings, P. J.; Hird, M. Introduction to Liquid Chistals, Chemistry and Physics; Taylor \& Francis Ltd: London, UK, 1997. (b) Tschierske, C. J. Mater, Chem. 2001, I, 2647.

4. (a) Foster, S.; Plantenberg, T. Angew. Chem. Int. Ed. 2002, 4I, 688. (b) Foster, S.; Anlonietti, M, Adr. Mater. 1998, J0, 195.

5. Khandpur, A. K.; Foster, S.; Bates, F. S.; Hamley, I, W;; Ryan, A. J.; Bras, W.; Almdal, K.; Mortensen, K. Macromolectles 1995 
28,8796

6. Zeng, F.; Zimmerman, S. C. Chent. Rev. 1997, 97, 1681.

7. (a) Brunsveld, L.; Folmer, B. J. B.; Meijer, E. W.; Sijbesma, R. P. Chem. Rev. 2001, 101, 4071; (b) Jo, H. J.; Jung, S. H,; Kim, H.-J. Bull. Korean Chem. Soc. 2004, 25, 1869.

8. (a) Hennigar, T. L.; MacQuarrie, D. C.; Losier, P.; Rogers, R. D.; Zaworotko, M. J. Angew. Chem. Int. Ed. 1997, 36, 972; (b) Park, K.-M.; Lee, E.; Roh, S.-G.; Kim, J.; Kim, K. Btil. Korean Chen. Soc. 2004, 25. 1711 .

9. Kaes, C.; Hosseini, M. W.; Rickard, C. E. F.; Skelton, B. W.; White, A. H. Angew: Chem. Int, Ed. 1998, 37,920.

10. Cui, Y,; Lee, S. J.; Lin, W. J. Am. Chem. Soc. 2003, 125,6014.

II. (a) Tschierske, C.J. Mater. Chem. 1998, 8,1485 ; (b) Berresheim, A. J.; Müller, B.; Müllen, K. Chen. Rev 1999, 99, 1747; (c) Steffen, W.; Köhler, B.; Altmann, M.; Scherf. U.; Stitzer, K.; Loye, H.-C.; Bunz, U. H. F. Chem. Ezm: J. 2001, 7, 117. (d) Jeneckhe, S. A.; Chen, X. L. Science 1999, 283, 372.

12. (a) Lee, M.; Yoo, Y.-S. J. Mater: Chem. 2002, 12, 2161. (b) Stupp, S. I. Curr Opin. Colloid Interface Sci. 1998, 3, 20.

13. (a) Semenov, A. N.; Vasilenko, S. V. Sov. Phys. JETP 1986, 6.3(1), 70. (b) Semenov, A. N. Mol. Cryst. Lig. Cryst. 1991, 209, 191. (c) Williams, D. R. M.; Fredrickson, G. H. Macromolectles 1992, 25, 3561. (d) Halperin, A. Macromolecules 1990, 23, 2724.

14. (a) Lee, M.; Cho, B.-K.; Kim, H.; Zin, W.-C. Angew: Chem. Int. Ed. 1998, 37,638 . (b) Lee, M.; Cho, B.-K.; Kim, H.; Yoon, J.-Y.; Zin. W.C. J. Am. Chen. Soc. 1998, 120,9168. (c) Lee, M.; Lee, D.-W.; Cho, B.-K.; Yoon, J.-Y.; Zin, W.-C. J. An. Chen. Soc. 1998, 120, 13258. (d) Lee, M.; Cho, B.-K.; Kang, Y.-S.; Zin, W.C. Macromolecules 1999, 32, 7688. (e) Lee, M.; Cho, B.-K.; Kang, Y.-S.; Zin, W.-C. Macromolectles 1999, 32,8531.

15. (a) Vriezema, D. M.; Hoogboom, J.; Velonia, K.; Takazawa, K.; Christianen, P. C. M.; Maan, J. C.; Rowan, A. E.; Nolte, R. J. M. Angew: Chem., Int. Ed. 2003, 42, 772. (b) Lee, M.; Jang. D.-W.; Kang, Y.-S.; Zin. W.-C. Adl Mater. 1999, H. 1018. (c) de Gans, B. J.; Wiegand, S.; Zubarev, E. R.; Stupp, S. I. J. Phys. Chem. B 2002, 106, 9730. (c) Tu, Y.; Wan, X.; Zhang, D.; Zhou, Q.; Wu, C. J. J. Am. Chem. Soc. 2000, 122, 10201 .

16. Lee, M.; Oh, N.-K. J. Mater Chem. 1996, 6, 1079.

17. (a) Hamley, I. W.; Ropp, K. A.; Rosedale, J. H.; Bates, F. S.; Almdal, K.; Mortensen, K. Macromolecules 1993, 26, 5959. (b) Bates, F. S.; Schulz, M. F.; Khandpur, A. K.; Foster, S.; Rosedale, J. H.; Almdal, K.; Mortensen, K. Farado; Discuss., Chem. Soc. $1994,98,7$.

18. Ryu, J.-H.; Oh, N.-K.; Zin, W.C.; Lee, M. J. Am. Chen. Soc. 2004, 126, 355I.

19. Malsen, M. W.; Bates, F. S. Macromolecules 1996, 29, 1091.

20. Müller, M.; Schick, M. Macromolecules 1996, $29,8900$.

2I. Raphael, E.; de Genn, P. G. Makromol. Chem., Macromol. Symp. $1992,62,1$.

22. Burger, C.; Micha, M. A.; Oestereich, S.; Föster, S.; Antonietti, M. Etrophys. Lett. 1998, 42,425.

23. Ahn, J.-H.; Zin, W.-C. Mocronolectles 2000, 33, 64I.

24. Raez, J.; Tomba, J. P.; Manners, I.; Winnik, M. A. J. Am. Chem. Soc. 2003, 125,9546.

25. Luzzati, V.; Tardieu, A.; Gulik-Krzwicki, T. Natme 1968, 217, 1028.

26. Kekicheff, P.; Tiddy, G. J. T. J. Phys. Chem. 1989, 93, 2520.

27. Fairhurst C. E.; Fuller, S.; Gray, J.; Holmes, M. C.; Tiddy, G. J. T. Handbook of Liquid Crystals; Demus, D.; Goodby, J.; Gray, G. W.; Spiess, H.-W.; Vill, V., Eds.; Wiley-VCH: Weirheim, Germany, 1998; Vol. 3,p 341.

28. (a) Yoo, Y,-S.; Choi, J.-H.; Song, J.-H.; Oh, N.-K.; Zin, W.-C.; Park, S.; Chang. T.; Lee, M. J. Am. Chem. Soc. 2004, 126, 6294. (b) Kraft, A.; Grimsdale, A. C.; Holmes, A. B. Angen. Chen. Int. Ed. 1998, 37, 402. (c) Bunz, U. H. F. Acc. Chem. Res. 2001, 34, 998. (d) Breen, C. A.; Deng, T.; Breiner, T.; Thomas, E. L.; Swager, T. J. Am. Chem. Soc, 2003, $125,9942$.

29. (a) Alexandridis, P; Lindman, B. Amphiphilic Block Copolymer,
Self-Assembly and Applicaitions; Elservier: New York, 2000. (b) Antonietti, M.; Förster, S. Act. Mater 2003, 15, 1323. (c) Discher, D. E.; Eisenber, A. Science 2002, 207, 967. (d) Förster, S.; Plantenberg. T. Angew. Chem. Int. Ed. 2002, 41,688.

30. Zhou, S.; Burger, C.; Chu, B.; Sawamura, M.; Nagahama, N.; Toganoh, M.; Hackler, U. E.; Isobe, H.; Nakamura, E. Science 2001, 201, 1944.

31. Chu, B. Laser Light Scattering, 2nd ed.; Academic Press: New York, 1991.

32. (a) Vriezema, D. M.; Hoogbum, J.; Velonia, K.; Takazawa, K.; Christianten, P. C. M.; Maan, J. C.; Rowan, A. E.; Nolte, R. J. M. Angew, Chem. Int. Ed, 2003, 42, 772-776. (b) Holder, S. J.; Hioms, R. C.; Sommerdijk, N. A. J. M.; Williams, S. J.; Jones, R. G.; Nolte, R. J. M. Cheni Commun. 1998, 1445.

33. Stadler, R.; Auschra, C.; Beckmann, J.; Krappe, U.; Voigt-Martin, I.; Leibler, L. Macromolecules $1995,28,3080$.

34. (a) Lee, M.; Oh, N.-K.; Choi, M.-G. Polym, Bull. 1996, 37,51 I. (b) Oh, N.-K.; Zin, W.-C.; Im, J.-H.; Ryu, J.-H.; Lee, M. Chem. Commun. 2004, 1092.

35. (a) Schwab, M.; Stuehn, B. Phys. Rev: Left. 1996, 76, 924. (b) Sakamota, N.; Hashimoto, T.; Han, C. D.; Vaidya, N. Macronolecriles 1997, 30, 1621.

36. (a) Lee, M.; Cho, B.-K.; Jang, Y.-G.; Zin, W.-C. J. Am. Chem. Soc, 2000, 122, 7449. (b) Cho, B.-K.; Chung, Y.-W,; Lee, N. Macromolectles 2005, 38, 10261 .

37. (a) Cho, B.-K.; Lee, M.; Oh, N.-K.; Zin, W.-C. J. Am. Chem. Soc. 2001, 123, 9677. (b) Cho, B.-K.; Chung, Y.-W.; Lee, M. Macromolecules $2005,35,10261$.

38. (a) Jin, L.-Y.; Bae, J.; Ahn, J.-H.; Lee, M. Chem. Commun, 2005, I197. (b) Kao, H. M.; Stefanescu, A. D.; Wooley, K. L.; Schaefer, J. Macromolecules 2000, 33, 62 l4. (c) Bockstaller, M.; Fytas, G.; Weoner, G. Macromolectles 2001, 34, 3497. (d) Acierno, D.; Amendola, E.; Concilio, S.; Fresa, R.; Jannelli, P.; Vacca, P. Macromolectles 2000, 33, 9376. (e) Hamley, I. W.; Castelletto, V; Lu, Z. B.; Imrie, C. T.; Itoh, T.; Al-Hussein, M. Macromolectles 2004, 37, 4798. (I) Bragg, R. A.; Clayden, J. Org. Lett. 2000, 2, $335 \mathrm{I}$.

39. (a) Lee, M.; Cho, B.-K.; Ihn, K. J.; Lee, W.-K.; Oh, N.-K.; Zin, W.-C. J. Am. Chen. Soc. 2001, I23, 4647. (b) Cho, B.-K.; Lee, M.; Oh, N.-K.; Zin, W.-C.J. Am. Chem. Soc. 2001, 123,9677.

40. (a) Jin, L. Y.; Ahn, J.-H.; Lee, M. J. Am. Chem. Soc. 2004, 126 , 12208. (b) Kenichi, T. Phys, Rev. Lett, 1995, 75, 1807. (c) Bohra, Y. K,; Olijnik, H.; Grosshans, W.; Holzapfel, W. B. Phys, Rev. Leti, 1981, 47, 1065.

4I. (a) Grayson, S. M.; Fréchet, J. M. J. Chem. Rev. 2001, 101, 3819. (b) Moore, J. S. Acc. Chem. Res. 1997, 30, 402. (c) Percec, V; Ahn, C.-H.; Ungar, G.; Yeardley, D. J. P.; Möller, M.; Sheiko, S. S. Nature 1998, 391, 161. (d) Schenning, A. P. H. J.; Elissen-Roman, C.: Weener, J. W.; Baars, M. W. P. L.; van der Gaast, S. J.; Meijer, E. W. J. Am. Chem. Soc. 1998, 120,8199 .

42. Gitsov, I. In Actances in Dendritic Macronolecules; Newkome, G. R., Ed.; Elsevier Science: Amsterdam, 2002; Vol. 5, pp 45-87.

43. (a) Gitsov, I.; Wooley, K. L.; Fréchet, J. M. J. Angew: Chem., Int. Ed. Engl, 1992, 31, 1200. (b) Gitsov, I.; Fréchet, J. M. J. Macromolecules 1993, 26, 6536. (c) van Hest, J. C. M.; Delnoye, D. A. P.; Baars, M. W. P. L.; van Genderen, M. H. P.; Meijer, E. W. Science 1995, 268, 1592.

44. (a) Percec, V.; Cho, W.-D.; Ungar, G; Yeardley, D. J. P. J. Ant. Chem. Soc. 2001, 123, 1302. (b) Yeardley, D. J. P.; Ungar, G; Percec, V.; Holerca, M. N.; Johansson, G. J. Am. Chem. Soc, 2000, 122, 1684. (c) Jang, C.-J.; Ryu, J.-H.; Lee, J.-D.; Sohn, D.; Lee, M. Chem. Mater. 2004, 16, 4226 .

45. (a) Eisenbach, C. D.; Heinemann, T.; Ribbe, A.; Stadler, E. Macromol. Symip. 1994, 77, 125. (b) Osaheni, J. A.; Jenekhe, S. A. J. An. Chem. Soc. 1995, $117,7389$.

46. Lee, M.; Cho, B.-K.; Oh, N.-K,; Zin, W.-C. Macromolecules 2001, 34, 1987.

47. Ryu, J.-H.; Bae, J.; Lee, M. Macromolecules 2005, 38, 2050. 